\title{
Comment on: "A novel approach to peatlands as archives of total cumulative spatial pollution loads from atmospheric deposition of airborne elements complementary to EMEP data: priority pollutants $(\mathrm{Pb}, \mathrm{Cd}, \mathrm{Hg})$ "
}

by Ewa Miszczak, Sebastian Stefaniak, Adam Michczyński, Eiliv Steinnes and Irena Twardowska.

\section{Authors}

De Vleeschouwer F. ${ }^{*}$, Baron S. ${ }^{2}$, Cloy J.M. ${ }^{3}$, Enrico M.., Ettler V. ${ }^{5}$, Fagel N. ${ }^{6}$, Kempter H. ${ }^{7}$, Kylander M. ${ }^{8}$, Li C. ${ }^{9}$, Longman J. ${ }^{10}$, Martinez-Cortizas A. ${ }^{11}$, Marx S. ${ }^{12}$, Mattielli N. ${ }^{13}$, Mighall T. ${ }^{14}$, Nieminen T.M. ${ }^{15}$, Piotrowska N. ${ }^{16}$, Pontevedra Pombal X. ${ }^{11}$, Pratte S. ${ }^{17}$, Renson V. ${ }^{18}$, Shotyk W. ${ }^{19}$, Shuttleworth E..$^{20}$, Sikorski J. ${ }^{16}$, Stromsoe N. ${ }^{21}$, Talbot J. ${ }^{22}$, von Scheffer C. ${ }^{23}$, D. Weiss $^{24,25}$, Zaccone C. ${ }^{25}$, Le Roux G. ${ }^{26}$

1. Instituto Franco-Argentino para el Estudio del Clima y sus Impactos (UMI IFAECI/CNRS-CONICET-UBA-IRD)

2. Laboratoire TRACES (CNRS, Université de Toulouse), France

3. Scotland's Rural College, Edinburgh, UK

4. Harvard John A. Paulson School of Engineering and Applied Science, Harvard University, Cambridge, MA, USA

5. Charles University, Prague, Czech Republic

6. AGEs, Département de Géologie, Université de Liège, Belgium

7. Welzheimer Str. 14, D-71566 Althuette, Germany

8. Department of Geological Sciences and the Bolin Centre for Climate Research, Stockholm University, Sweden

9. Geoscience Environnement Toulouse (CNRS-UPS-IRD-CNAP-CNES), France

10. School of Geography and the Environment, University of Oxford, UK

11. EcoPast (GI-1553), Universidad de Santiago de Compostela, Spain

12. GeoQuEST Research Centre, School of Earth, Atmospheric and Life Sciences, University of Wollongong, Australia

13. Laboratoire G-Time, Université Libre de Bruxelles, Belgium

14. School of Geosciences, University of Aberdeen, UK

15. Natural Resources Institute Finland Luke, Helsinki, Finland

16. Silesian University of Technology, Institute of Physics-CSE, GADAM Center, Gliwice, Poland

17. Department of Geography, School of Earth Sciences, Zhejiang University, Hangzhou, China

18. Research Reactor, University of Missouri, USA.

19. Department of Renewable Resources, University of Alberta, Edmonton, Canada

20. Department of Geography, University of Manchester, UK 
21. College of Engineering, IT and Environment, Charles Darwin University, Australia

22. Département de Géographie, Université de Montréal, Canada

23. Institute for Ecosystem Research, Kiel University, Germany

24. Imperial College London, UK

25. Princeton University, Princeton, USA

26. Department of Biotechnology, University of Verona, Italy

27. EcoLab, Université de Toulouse, CNRS, Toulouse, France

\footnotetext{
* Corresponding author: Dpto. de Ciencias de la Atmosfera y los Oceanos, FCEN, Universidad de Buenos Aires, Intendente Guiraldes 2160 - Ciudad Universitaria, Pabellon II - 2do. Piso, (C1428EGA) Ciudad Autonoma de Buenos Aires - Argentina.fdevleeschouwer@cima.fcen.uba.ar
}

\section{Abstract}

A recent paper by Miszczak et al. (2020) examines metal contamination in mires in Poland and Norway. The authors conclude that lead $(\mathrm{Pb})$ records in ombrotrophic peatlands cannot be used to reconstruct the chronological history of anthropogenic activities due to postdepositional mobility of the metal. We contest this general conclusion which stands in contrast with a significant body of literature demonstrating that $\mathrm{Pb}$ is largely immobile in the vast majority of ombrotrophic peatlands. Our aim is to reaffirm the crucial contribution that peat records have made to our knowledge of atmospheric $\mathrm{Pb}$ contamination. In addition, we re-iterate the necessity of following accepted protocols to produce reliable records of anthropogenic $\mathrm{Pb}$ contamination in environmental archives.

\section{Keywords}

Lead, immobility, ombrotrophic peatland, bog, geochemistry, enrichment factor, metal accumulation rate 


\section{1. INTRODUCTION}

2 Ombrotrophic peatlands are well-established archives of past atmospheric deposition of trace elements. After more than 40 years of investigation (see Table SI1), there is a consensus that $\mathrm{Pb}$ is largely immobile in ombrotrophic peatlands. We contend that some of the conclusions reached by Miszczak et al (2020) are based on misinterpretation or incorrect sampling and data analysis approaches. To avoid such confusion, we seek to clarify here how ombrotrophic peatlands have allowed the reconstruction of past patterns of atmospheric metal contamination in the environment. We however do not aim to provide a complete review of $\mathrm{Pb}$ in mires, because the trophic status of a peatland is crucial to studies of past atmospheric metal deposition (see Supplementary Material for further details), we refer to a selection of studies relevant to ombrotrophic peatlands, also known as bogs. Due to their high atmospheric fidelity, ombrotrophic peatlands have special utility for reconstructing metal contamination records. This was also the type of peatland investigated by Miszczak et al. (2020).

\section{THE BEHAVIOUR OF LEAD IN OMBROTROPHIC PEATLANDS}

While some studies have suggested that $\mathrm{Pb}$ can be mobilized in minerotrophic, riparian, drained or degraded peatlands (e.g. Syrovetnik et al., 2007; Smieja-Król et al., 2010, 2019; Rothwell, 2011; Broder and Biester, 2017) the majority of more than 40 years of literature suggests that $\mathrm{Pb}$ is largely immobile in pristine ombrotrophic peat profiles (e.g. De Vleeschouwer et al., 2010a; Marx et al., 2010, Shotyk et al., 2016a,b; Longman et al. 2018;

21 Fiałkiewicz-Kozieł et al., 2020 and references therein). Although Miszczak et al. (2020) cite literature to support their conclusion of $\mathrm{Pb}$ mobility in the bogs they examine, that literature pertains to minerotrophic or disturbed peatlands (e.g. Syrovetnik et al., 2007; Smieja-Król et al., 2010, 2019) and the processes that can promote Pb mobility in those systems are not applicable to ombrotrophic peatlands.

27 The similar elemental and isotopic trends encountered in ombrotrophic peat, lake sediment, ice and herbaria samples (e.g. Rosman et al., 1997; Weiss et al., 1999; Renberg et al., 2001; 
Farmer et al., 2002; Cloy et al. 2009; Bindler, 2011) and their agreement with anthropogenic emission patterns (e.g. Shotyk et al., 1998; Mighall et al., 2002; Kylander et al., 2006; De Vleeschouwer et al., 2009a; Marx et al., 2010; Bindler 2011; Cloy et al., 2008, 2009; Allan et al., 2013; Martínez-Cortizas et al., 2016) provide a body of evidence supporting the view that $\mathrm{Pb}$ is largely immobile in bogs. Significantly, stable $\mathrm{Pb}$ isotopes records from bogs have consistently been found to accurately reflect temporal variability in source signatures in numerous studies (e.g. in reference op. cit.). This would not be the case if post-depositional mobility/isotope mixing were taking place. Furthermore, in most ombrotrophic peat cores ${ }^{210} \mathrm{~Pb}$ ages, as determined from the constant rate of supply (CRS) age-depth models (Appleby and Oldfield, 1978; Appleby, 2001), are in very good agreement with pollen chronological markers (Appleby et al., 1997), fallout radionuclide chronostratigraphic makers (e.g. from ${ }^{14} \mathrm{C}$ Bomb Pulse Curve, ${ }^{137} \mathrm{Cs}$ and ${ }^{241} \mathrm{Am}$ ), and tephrochronology (e.g. Goodsite et al., 2001; Piotrowska et al. 2009; Li et al., 2017; Davies et al., 2018), providing prima facie evidence that Pb and its isotopes are largely immobile in bogs. Experimental studies lend further support to this (e.g. Vile et al., 1999; Novak et al., 2001). For example, Pb concentrations in the aqueous phase of ombrotrophic peatlands are low $(<0.01 \%$ of total $\mathrm{Pb})$, while the limited vertical water movement in bogs together with the size of the metal-containing particles in solution limits $\mathrm{Pb}$ redistribution (e.g. Shotyk et al., 2016b). Down-washing experiments have also demonstrated that $\mathrm{Pb}$ has limited mobility (Hansson et al. 2014, 2015). The limited mobility that may occur is not sufficient to compromise the use of $\mathrm{Pb}$ to reconstruct pollution histories over millennia. We note, however, the spatial distribution of $\mathrm{Pb}$ must be carefully addressed in cases where decomposition and compression integrate signals over longer (decadal and more) timespans 51 (Bindler et al, 2004; Martinez Cortizas et al., 2012). Additionally, Pb behaviour in ombrotrophic peats has been demonstrated to differ from that of mobile elements such as $\mathrm{Zn}$ which, in 53 contrast to $\mathrm{Pb}$, displays evidence of vertical diffusion/advection as well as upward plant uptake 54 (e.g. Shotyk 1988; Twardowska et al., 1999; Nieminen et al., 2002; Weiss et al., 2007). 
In summary, there is a significant body of evidence demonstrating that $\mathrm{Pb}$ is largely immobile in bog profiles (see Table S1 and Supplementary Material) that stands in contrast to the conclusions of Miszczak et al. (2020).

\section{HOW TO USE LEAD DATA TO ACCURATELY RECONSTRUCT HISTORICAL} CONTAMINATION

In the following sections we outline what we consider to be the best practices to ensure accurate reconstruction of atmospheric $\mathrm{Pb}$ deposition. We also discuss appropriate approaches to use $\mathrm{Pb}$ pollution records constructed from peatlands to examine contaminant sources and to compare with emissions data. The approaches we outline are well established and have been described before (e.g. Givelet et al., 2004; De Vleeschouwer et al., 2010b). We hope that this overview corrects any misapprehensions arising from the approaches used by Miszczak et al. (2020).

\subsection{Sampling and sub-sampling - Data resolution and geochronology}

Correct coring and sub-sampling protocols are important for accurately reconstructing metal contamination records from mires. The slow accumulation rate of ombrotrophic peatlands means that peat sections on the order of one vertical centimeter can represent decades of metal accumulation. For example, in European ombrotrophic peatlands, long-term mean peat accumulation rates (i.e. excluding surface vegetation growth) have been estimated to range from c. 0.18 to $1 \mathrm{~mm} \mathrm{yr}{ }^{-1}$ (e.g. Gorham, 1991; Mäkilä, 1997; Malmer and Wallén, 2004; Pontevedra-Pombal, et al., 2017) depending on the vegetation and climate (e.g. Charman et al., 2013; Pontevedra-Pombal et al., 2019). Because of this, it is commonplace for studies to both sample and date the living vegetation at the bog surface (e.g. Farmer et al., 2006; Kempter et al. 2007; Olid et al., 2008). This point was illustrated by Givelet et al. (2004) who stated: "the historical record of atmospheric $\mathrm{Pb}$... can depend to a large extent on the methods used to collect, handle, and prepare the samples for analysis". As a result, high-resolution subsampling and dating are required to reconstruct decadal-scale atmospheric pollution records. 
Here Miszczak et al. (2020) compare metal contaminants in their peat records to European Monitoring and Evaluation Program (EMEP) data (annual trace metal emissions, https://www.emep.int). Although potentially a very useful undertaking, their sampling approach unfortunately greatly reduces the utility of their comparison. This is because Miszczak et al. (2020) followed the coring protocol of Steinnes and Sjøbakk (2005) where "Sphagnum moss ... and other plant material growing on the surface were removed...before the coring, and the reference surface level is thus the interface moss/peat. The thickness of the Sphagnum layer, if present, was always less than $10 \mathrm{~cm}$ ". In other words, the authors removed the living/surface vegetation which is an integral part of the ombrotrophic peat deposit, potentially accumulating decades of information.

Given the slow accumulation rates of bogs, the 40 years of EMEP data are likely, at best, to represent approximately $4 \mathrm{~cm}$ of peat accumulation (if surface vegetation is excluded and assuming a $1 \mathrm{~mm} \mathrm{yr}^{-1}$ peat accumulation rate). Therefore, the sampling resolution of Miszczak et al. (2020), where peats were subsampled in multi-centimeter increments, combined with their limited use of radionuclide dating, preclude any assessment of recent $\mathrm{Pb}$ deposition or comparison with EMEP data from their study. This is especially the case if surface vegetation were removed. Slow growth rates, combined with the demonstrated importance of surface vegetation in accumulating metal contaminants means that Miszczak et al. (2020) assumption that the peat/vegetation interface represents the year of coring (in that case 1999) is incorrect.

Their approach therefore leads to large uncertainties in chronology and any inventory calculations performed thereafter. As previously stated, we consider comparing EMEP data with data from ombrotrophic peatlands to be a very worthwhile undertaking, but it requires high-resolution sub-sampling and dating, which is unfortunately not achieved by Miszczak et al. (2020).

\subsection{Interpreting data in elemental ratios, enrichment factors (EFs) and metal} accumulation rates, 
110 Reconstructing $\mathrm{Pb}$ contamination in ombrotrophic peatlands requires an understanding of how

111 they respond to environmental change. This is because changes in $\mathrm{Pb}$ concentrations may

112 result from changes in the peat bog density/accumulation rate rather than changes in the 113 extent of contamination. In the following section we outline the importance of understanding 114 density changes in peat records and the need to consider the variability in natural $\mathrm{Pb}$ from aeolian mineral dust deposition. We provide a brief overview of techniques to account for such changes, allowing $\mathrm{Pb}$ to be reliably used as a tracer of past anthropogenic activity.

\subsubsection{Density, accumulation rate and $\mathrm{Pb}$ concentration}

119 The importance of understanding and accounting for changes in peat density and dust input 120 are illustrated by De Vleeschouwer et al. $(2009 a, b)$ in their study of the Slowinskie Blota 121 ombrotrophic peatland (Poland). In this peatland, a section of higher than average bulk density 122 was present between 50 and $35 \mathrm{~cm}$ depth (De Vleeschouwer et al., 2009a,b). It corresponds

123 to the timing of the Little Ice Age, when colder temperatures promoted a decrease in peat 124 accumulation rates coeval with increased windiness and dune activity (i.e. increased aeolian 125 lithogenic inputs). This combination of reduced organic accumulation rates and increased dust 126 input resulted in an increase in bulk density. The effect of these changes was an increase in $127 \mathrm{~Pb}$ concentration within the peat profile. Although part of this $\mathrm{Pb}$ increase is attributable to 128 increased pollution in the Industrial Revolution, the majority of the $\mathrm{Pb}$ increase results from the 129 decrease in peat accumulation causing an apparent increase in pollution $\mathrm{Pb}$ accumulation.

130 This occurs because that section of the peat profile represents a greater period of time than 131 sections below $50 \mathrm{~cm}$ depth or above $35 \mathrm{~cm}$ depth. In addition, increased dust inputs during

132 the drier conditions of the Little Ice Age mean there was an increase in natural $\mathrm{Pb}$ input during 133 that period. Miszczak et al. (2020) incorrectly assumed the increase in $\mathrm{Pb}$ in the Slowinskie 134 Blota peatland at that time resulted from the movement of $\mathrm{Pb}$ from higher in the peat profile 135 (i.e., Pb mobility in the bog). But, by appropriately accounting for the change in density and 136 increased dust input during the Little Ice Age (i.e. using EFs accumulation rates and isotopic 137 ratios, which are discussed in the next section), De Vleeschouwer et al. (2009a) demonstrated 
138 the maximum $\mathrm{Pb}$ concentration in the Slowinskie Blota record occurred at AD 1960-70s, and

139 not between 50 and $35 \mathrm{~cm}$ depth as the raw $\mathrm{Pb}$ concentration data would suggest. The

140 maximum $\mathrm{Pb}$ contamination therefore coincided precisely with maximum $\mathrm{Pb}$ emissions from

141 leaded gasoline, just prior to $\mathrm{Pb}$ being banned and phased out beginning in the 1980s (e.g.

142 Pacyna and Pacyna, 2000). De Vleeschouwer et al. (2009a,b), match the known history of

143 anthropogenic $\mathrm{Pb}$ emissions in Europe clearly demonstrating that it is not related to any post-

144 depositional mobility. The approach to accurately reconstruct $\mathrm{Pb}$ contamination (as separate

145 from total $\mathrm{Pb}$ concentrations) is outlined in the following section.

\subsection{2. $\mathrm{Pb}$ as a tracer of past anthropogenic activity}

148 Since the pioneering paper of Lee and Tallis (1973), practices have developed to ensure the accurate use of trace metal data to reconstruct past environmental pollution. It has been

150 demonstrated that using concentration data to reconstruct past anthropogenic activity is 151 problematic because, as shown above, peat accumulation rates alter total $\mathrm{Pb}$ concentrations.

152 Additionally, because the rate of dust deposition in bogs (from wind erosion of soils) varies, it

153 is necessary to separate natural $\mathrm{Pb}$ in dust from anthropogenic $\mathrm{Pb}$. Therefore, it is common 154 practice to use metal to lithogenic element ratios, enrichment factors (EFs), or elemental mass 155 accumulation rates (e.g. Shotyk et al., 1998; Le Roux et al., 2010; Allan et al., 2013) to 156 reconstruct contamination histories. These approaches are important to avoid 157 misinterpretations based on examining concentration data alone. Miszczak et al. (2020) did 158 not apply these standard approaches. By comparison De Vleeschouwer et al. (2009a) use EFs 159 and $\mathrm{Pb}$ accumulation rates (combined to $\mathrm{Pb}$ isotopes and high-resolution sampling and dating 160 including the surface vegetation) to come to a different set of conclusions regarding the utility 161 of Polish ombrotrophic peatlands for reconstructing $\mathrm{Pb}$ contamination histories. Consequently 162 the latter represents a more accurate picture of the extent of $\mathrm{Pb}$ contamination in Poland over 163 the past 1400 years, demonstrating i) the $\mathrm{Pb}$ accumulation rate in the topmost centimeter of 164 the peat is of the same order of magnitude as 2009 European $\mathrm{Pb}$ deposition 165 (www.msceast.org, www.emep.int), ii) the main sources of anthropogenic $\mathrm{Pb}$ are from 
166 metallurgy, coal and gasoline and, iii) the peak in $\mathrm{Pb}$ contamination matches the history of

167 European $\mathrm{Pb}$ emissions. That work therefore provides another example amongst many others, 168 (Table SI1) of $\mathrm{Pb}$ being largely immobile in ombrotrophic peatlands and shows peatlands to 169 be excellent recorders of anthropogenic activities.

\section{4. CONCLUSIONS}

172 Due to their fidelity ombrotrophic peatlands have been extensively used to study current and 173 past patterns of atmospheric metal contamination and metal use, in particular for $\mathrm{Pb}$. Despite 174 their utility there are some key considerations required when constructing contamination 175 histories from bogs. The aim of this comment was to highlight some these considerations. The 176 impetus for this arose from the recent paper by Miszczak et al (2020) who used nonstandard 177 sampling and analysis techniques and, as a result, came to what we consider to be erroneous 178 conclusions. Additional discussion on the effect of $\mathrm{pH}$ on $\mathrm{Pb}$ mobility and the relationship 179 between peat age and the history of $\mathrm{Pb}$ contamination is provided in the supplementary 180 material. Over the past 40 years many investigators have developed or applied a range of 181 analysis and sampling techniques necessary to construct metal contamination records in 182 ombrotrophic peatlands. These approaches include undertaking high resolution sampling and 183 dating, including sampling the living vegetation of the surface of bogs and the use of short-

184 lived radionuclides (such as ${ }^{210} \mathrm{~Pb}$ ) to accurately reconstruct metal contamination over the past $185 \sim 100$ years or less. They also include calculating enrichment factors (EFs), elemental ratios,

186 or using accumulations rates (as opposed to raw metal concentration data) to take account of 187 changes in peat density/growth rates and changes in natural metal input. Studies of $\mathrm{Pb}$ 188 contamination have also benefitted from the use of $\mathrm{Pb}$ isotopes to decipher emission sources 189 at a regional to continental scale. Many of these steps are also necessary when accurately 190 determining contaminate loads and patterns in other environments including in ice, lakes and 191 soils and within direct atmospheric samples. We therefore wish to reiterate the particular value 192 of ombrotrophic peats for reconstructing atmospheric metal contaminant chronologies due to 193 their wide distribution and high fidelity. We maintain that 40 years of literature demonstrate that 
$194 \mathrm{~Pb}$ is largely immobile in ombrotrophic peatlands (i.e. bogs) and that peat cores extracted from

195 this type of mire represent reliable archives for reconstructing past natural changes in $\mathrm{Pb}$

196 deposition from natural processes and anthropogenic activity. The approach is supported by

197 experimental work and similar reconstructions of metal contamination in other environmental

198 archives (herbarium samples, lake sediments, ice cores). We conclude by noting that

199 reconstructions of $\mathrm{Pb}$ contamination from bogs provide unequivocal evidence of the global

200 scale of atmospheric $\mathrm{Pb}$ contamination and a reliable record of the timing of changes in

201 atmospheric deposition extending from pre-history until the present day.

202

203 


\section{ACKNOWLEDGEMENTS}

We are thankful to P.G. Appleby, R. Bindler, J. Sonke, B. Smieja-Krol and three anonymous reviewers for their constructive comments.

\section{REFERENCES}

Allan, M., Le Roux, G., De Vleeschouwer, F., Bindler, R., Blaauw, M., Fagel N., 2013. High-resolution reconstruction of atmospheric deposition of trace metals and metalloids since AD 1400 recorded by ombrotrophic peat cores in Hautes-Fagnes, Belgium. Environ. Pollut. 178, 381-394.

Appleby, P.G., 2001. Chronostratigraphic techniques in recent sediments, in Last, W.M. and Smol, J.P. (Eds.), Tracking Environmental Change Using Lake Sediments: Basin Analysis, Coring, and Chronological Techniques, Vol. 1, Kluwer Academics, pp. 171-203.

Appleby, P.G., Oldfield, F., 1978. The calculation of lead-210 dates assuming a constant rate of supply of unsupported ${ }^{210} \mathrm{~Pb}$ to the sediments. Catena $5,1-8$.

Appleby, P.G., Shotyk, W., Fankauser, A., 1997. Lead-210 age dating of three peat cores in the Jura Mountains, Switzerland. Water Air Soil Pollut. 100, 223-231.

Bindler, R. 2011. Contaminated lead environments of man: reviewing the lead isotopic evidence in sediments, peat, and soils for the temporal and spatial patterns of atmospheric lead pollution in Sweden. Environ. Geochem. Health 33, 311-329

Bindler, R., Klarqvist, M., Klaminder, J., Förster, J. 2004. Does within-bog variability of mercury and lead constrain reconstruction of absolute deposition rates from single peat records? The example of Store Mosse, Sweden. Gobla Biogechem. Cycles 18, GB3020.doi:10.1029/2004GB002270.

Broder, T, Biester, H, 2017. Linking major and trace element concentrations in a headwater stream to DOC release and hydrologic conditions in a bog and peaty riparian zone. Appl. Geochem. 87, 188-201,

Charman, D., Beilman, D.W., Blaauw, M., Booth, R.K., Brewer, S., Chambers, F.M., Christen, J.A., Gallego-Sala, A., Harrison, S.P., Hughes, P.D.M., Jackson, S.T., Korhola, A., Mauquoy, D., Mitchell, F.J.G., Prentice, I.C., van der Linden, M., De Vleeschouwer, F., Yu, Z.C., Alm, J., Bauer, I.E., Corish, Y.M.C., Garneau, M., Hohl, V., Huang, Y., Karofeld, E., Le Roux, G., Loisel, J., Moschen, R., Nichols, J.E., Nieminen, T.M., MacDonald, G.M., Phadtare, N.R., Rausch, N., Sillasoo, Ü., Swindles, G.T., Tuittila, E.-S., Ukonmaanaho, L., Väliranta, M., van Bellen, S., van Geel, B., Vitt, D.H., Zhao, Y. 2013. Carbon-cycle implications of climate-driven changes in peat accumulation during the last millennium. Biogeosciences 10, 929-944.

Cloy, J.M., Farmer, J.G., Graham, M.C., MacKenzie, A.B., Cook, G.T., 2008. Historical records of atmospheric Pb deposition in four Scottish ombrotrophic peat bogs: An isotopic comparison with other records from western Europe and Greenland. Glob. Biogeochem. Cycle 22, GB2016.

Cloy, J.M., Farmer, J.G., Graham, M.C., MacKenzie, A.B. 2009. Retention of As and Sb in ombrotrophic peat bogs: records of $\mathrm{As}, \mathrm{Sb}$ and $\mathrm{Pb}$ deposition at four Scottish sites. Environ. Sci. Technol. 43, 1756-1762.

Davies, L.J., Appleby, P., Jensen, B.J.L., Magnan, G., Mullan-Boudreau, G., Noernberg, T., Shannon, B., Shotyk, W., van Bellen, S., Zaccone, C., Froese, D.G., 2018. High-resolution age modelling of peat bogs from northern Alberta, Canada, using pre- and post-bomb ${ }^{14} \mathrm{C},{ }^{210} \mathrm{~Pb}$ and historical cryptotephra. Quat. Geochronol. 47,138162.

De Vleeschouwer, F., Fagel, N., Cheburkin, A., Pazdur, A., Sikorski, J., Mattielli, N., Renson, V., Fialkiewicz, B., Piotrowska, N., Le Roux, G., 2009a. Anthropogenic impacts in North Poland over the last 1300 years - A record of $\mathrm{Pb}, \mathrm{Zn}, \mathrm{Cu}, \mathrm{Ni}$ and $\mathrm{S}$ in an ombrotrophic peat bog. Sci. Total Environ. 407, 5674-5684.

De Vleeschouwer, F., Piotrowska, N., Sikorsky, J., Pawlyta, J., Cheburkin, A.K., Le Roux, G., Lamentowicz, M., Fagel, N., Mauquoy, D., 2009b. Multiproxy evidence of 'Little Ice Age' palaeoenvironmental changes in a peat bog from northern Poland. Holocene 19, 625-637.

De Vleeschouwer, F., Le Roux, G., Shotyk, W., 2010a. Peat as an archive of atmospheric metal pollution: the example of $\mathrm{Pb}$ in Europe. in: Jackson, S., Charman, D. (Eds.). Peatland. PAGES Newsletter, April 2010, vol. $18,20-22$ 
De Vleeschouwer, F., Chambers, F.M., Swindles, G.T., 2010b. Coring and sub-sampling of peatlands for palaeoenvironmental research. in: De Vleeschouwer, F., Hughes, P., Nichols, J.,Chambers, F.M. (Guest Eds.), A review of protocols in peat palaeoenvironmental studies. Mires and Peat, vol. 7, article 1, 1-10.

Farmer, J.G., Eades, L.J., Atkins, H., Chamberlain, D.F., 2002. Historical trends in the lead isotopic composition of archival Sphagnum mosses from Scotland (1838-2000). Environ. Sci. Technol. 36, 152-157.

Farmer, J.G., Graham, M.C., Yafa, C., Cloy, J.M., Freeman, A.J. and MacKenzie, A.B., 2006, Use of ${ }^{206} \mathrm{~Pb} /{ }^{207} \mathrm{~Pb}$ ratios to investigate the surface integrity of peat cores used to study the recent depositional history and geochemical behaviour of inorganic elements in peat bogs, Glob. Planet. Change, 53, 240-248.

Fiałkiewicz-Kozieł, B., Łokas, E., Gałka, M., Kołaczek, P., De Vleeschouwer, F., Le Roux, G., Smieja-Król B. (2020). Influence of transboundary transport of trace elements on mountain peat geochemistry (Sudetes, Central Europe). Quat. Sci. Rev. 230, 106162.

Givelet, N., Le Roux, G., Cheburkin, A., Chen, B., Frank, J., Goodsite, M., Kempter, H., Krachler, M., Noernberg, T., Rausch, N., Rheinberger, S., Roos-Barraclough, F., Sapkota, A., Scholz, C., Shotyk, W., 2004. Suggested protocol for collecting, handling and preparing peat cores and peat samples for physical, chemical, mineralogical and isotopic analyses. J. Environ. Monit. 6, 481-492.

Goodsite, M.E., Rom, W., Heinemeier, J., Lange, T., Ooi, S., Appleby, P.G., Shotyk, W., Van der Knapp, W.O., Lohse, C., Hansen, T.S., 2001. High-resolution AMS ${ }^{14} \mathrm{C}$ dating of post-bomb peat archives of atmospheric pollutants. Radiocarbon 43, 453-473.

Gorham, E., 1991. Northern peatlands: role in the carbon cycle and probable responses to climatic warming. Ecol. Appl. 1, 182-195

Hansson, S.V., Kaste, J.M., Chen, K., Bindler, R., 2014. Beryllium-7 as a natural tracer for short-term downwash in peat. Biogeochemistry 119, 329-339.

Hansson, S.V., Tolu, J., Bindler, R. (2015). Downwash of atmospherically deposited trace metals in peat and the influence of rainfall intensity: an experimental test. Sci. Total Environ. 506, 95-101.

Hughes, P.D.M., Mauquoy, D., Barber, K.E. Langdon, P.G., 2000. Mire-development pathways and palaeoclimatic records from a full Holocene peat archive at Walton Moss, Cumbria, England. Holocene 10, 465-479.

Kempter, H., Frenzel, B., 2007. The geochemistry of ombrotrophic Sphagnum species growing in different microhabitats of eight German and Belgian peat bogs and the regional atmospheric deposition. Water Air Soil Pollut. 184, 29.

Kylander, M.E., Weiss, D.J., Peiteado Varela, E., Taboada Rodriguez, T., Martinez-Cortizas, A. 2006. Archiving anthropogenic lead pollution in ombrotrophic peatlands. in: Martini, P.I., Chestworth, W., Martinez-Cortizas, A. (Eds.), Peatlands: basin evolution and depository of records on global environmental and climatic changes. Elsevier, pp. 479-497.

Lee, J., Tallis, J., 1973. Regional and historical aspects of lead pollution in Britain. Nature 245, 216-218.

Le Roux, G., De Vleeschouwer, F., 2010. Preparation of peat samples for inorganic geochemistry used as palaeoenvironmental proxies. in: De Vleeschouwer, F., Hughes, P., Nichols, J., Chambers, F.M. (Guest Eds.), A review of protocols in peat palaeoenvironmental studies. Mires and Peat, vol. 7, article 4, 1-9.

Li, C., Le Roux, G., Sonke, J., van Beek, P., Souhaut, M., Van der Putten, N., De Vleeschouwer, F., 2017. Recent ${ }^{210} \mathrm{~Pb},{ }^{137} \mathrm{Cs}$ and ${ }^{241} \mathrm{Am}$ accumulation in an ombrotrophic peatland from Amsterdam Island (Southern Indian Ocean). J. Environ. Radioact. 175-176, 164-169.

Longman, J., Veres, D., Finsinger, W., Ersek, V., 2018. Exceptionally high levels of lead pollution in the Balkans from the Early Bronze Age to the Industrial Revolution. Proc. Natl. Acad. Sci. U. S. A. 115, E5661-E5668.

Mäkilä, M., 1997. Holocene lateral expansion, peat growth and carbon accumulation on Haukkasuo, a raised bog in southeastern Finland. Boreas 26,1-14.

Malmer, N., Wallén, B., 2004. Input rates, decay losses and accumulation rates of carbon in bogs during the last millennium: internal processes and environmental changes. Holocene 14, 111-117.

Martinez-Cortizas, A., López-Merino, L., Bindler, R., Mighall, T., Kylander, M.E., 2016. Early atmospheric metal pollution provides evidence for Chalcolithic/Bronze Age mining and metallurgy in southwestern Europe. Sci. Total Environ. 545, 398-406. 
Martínez Cortizas, A., Peitedo Varela, E., Bindler, R., Biester, H., Cheburkin, A. 2012. Reconstructing historical Pn and $\mathrm{Hg}$ pollution in NW Spain using multiple cores from Chao de Lamoso bog (Xistral Mountains). Geochi. Cosmochim. Acta 82, 68-78.

Marx, S.K., Kamber, B.S., McGowan, H.A. and Zawadzki, A. 2010. Atmospheric pollutants in alpine peat bogs record a detailed chronology of industrial and agricultural development on the Australian continent. Environ. Pollut. 158, 1615-1628.

Mighall, T.M., Abrahams, P.W., Grattan, J.P., Hayes, D., Timberlake, S., Forsyth, S., 2002. Geochemical evidence for atmospheric pollution derived from prehistoric copper mining at Copa Hill, Cwmywtwyth, mid-Wales. Sci. Total Environ. 292, 69-80.

Miszczak, E., Stefaniak, S., Michczyński, A., Steinnes, E., Twardowska, I., 2020. A novel approach to peatlands as archives of total cumulative spatial pollution loads from atmospheric deposition of airborne elements complementary to EMEP data: priority pollutants (Pb, Cd, Hg). Sci. Total Environ. 705, 135776.

Novak, M., Zemanova, L., Voldrichova, P., Stepanova, M., Adamova, M., Pacherova, P., Komarek, A., Krachler, A., Prechova, E., 2011. Experimental evidence for mobility/immobility of metals in peat. Environ. Sci. Technol. 45, 7180-7187.

Nieminen, T.M., Ukonmaanaho, L., Shotyk, W., 2002. Enrichments of Cu, Ni, Zn, Pb and As in an ombrothrophic peat bog near a Cu-Ni smelter in Southwest Finland. Sci. Total Environ. 292, 81-89.

Olid, C., Garcia-Orellana, J., Martinez-Cortizas, A., Masqué, P., Peiteado, E., Sanchez-Cabeza, J.-A., 2008. Role of surface vegetation in ${ }^{210} \mathrm{~Pb}$-dating of peat cores.

Pacyna, J.M., Pacyna, E.G., 2000. Atmospheric emissions of anthropogenic lead in Europe: improvements, updates, historical data and projections. GKSS report no. 2000/31, Geesthacht, Germany.

Pontevedra-Pombal, X., Castro, D., Carballeira, R., Souto, M., López-Sáez, J.A., Pérez-Díaz, S., Fraga, M.I., Valcárcel, M., García-Rodeja, E., 2017. Iberian acid peatlands: types, origin and general trends of development. Mires and Peat 19, 1-19.

Pontevedra-Pombal, X., Castro, D., Souto, M., Fraga, I., Blake, W.H., Blaauw, M., López-Sáez, J.A., Pérez-Díaz, S., Valcárcel, M., García-Rodeja, E., 2019. 10,000 years of climate control over carbon accumulation in an Iberian bog (southwestern Europe). Geosci. Front. 10, 1521-1533.

Piotrowska, N., De Vleeschouwer, F., Sikorski, J., Pawlyta, J., Fagel, N., Le Roux, N., Pazdur, A., 2009. Intercomparison of radiocarbon bomb pulse and ${ }^{210} \mathrm{~Pb}$ age models. A study in a peat bog core from North Poland. Nucl. Instrum. Methods Phys. Res. Sect. B: Beam Interact. Mater. Atoms 268, 1163-1166.

Renberg, I. Bindler, R., Brännvall, M.L., 2001. Using the historical atmospheric lead-deposition record as a chronological marker in sediment deposits in Europe. Holocene 11, 511-516.

Rosman, K.J.R., Chisholm, W., Hong, S., Candelone, J. P., Boutron, C.F., 1997. Lead from Carthaginian and Roman Spanish mines isotopically identified in Greenland ice dated from 600 B.C. to 300 A.D. Environ. Sci. Technol. 31, 3413-3416.

Rothwell, J.J., Taylor, K.G., Evans M.G., Allott T.E.H., 2011. Contrasting controls on arsenic and lead budgets for degraded peatland catchment in Northern England. Environ. Pollut. 159, 3129-3133.

Shotyk, W., 1988. Review of the inorganic geochemistry of peats and peatland waters. Earth-Sci. Rev. 25, 95-176.

Shotyk, W., Weiss, D., Appleby, P. G., Cheburkin, A. K., Frei, R., Gloor, M., Kramers, J.D., Reese, S., van Der Knaap, W.O., 1998. History of atmospheric lead deposition since $12,370{ }^{14} \mathrm{C}$ yr BP from a peat bog, Jura mountains, Switzerland. Science 281, 1635-1640.

Shotyk, W., Appleby, P.G., Bicalho, B., Davies, L., Froese, D., Grant-Weaver, I., Krachler, M., Magnan, G., MullanBoudreau, G., Noernberg, T., Pelletier, R., Shannon, B., van Bellen, S., Zaccone, C., 2016a. Peat bogs in northern Alberta, Canada reveal decades of declining atmospheric Pb contamination, Geophys. Res. Lett. 43, 9964-9974.

Shotyk, W., Rausch, N., Nieminen, T.M., Ukonmaanaho, L., Krachler M., 2016b. Isotopic composition of Pb in peat and porewaters from three contrasting ombrotrophic bogs in Finland: Evidence of chemical diagenesis in response to acidification. Environ. Sci. Technol. 50, 9943-9951. 
Smieja-Król, B, Fiałkiewicz-Kozieł, B, Sikorski, J, Palowski, B., 2010. Heavy metal behaviour in peat - a mineralogical perspective. Sci. Total Environ. 408, 5924-5931.

Smieja-Król, B, Fiałkiewicz-Kozieł, B, Michalska, A, Krzykawski, T, Smołka-Danielowska, D., 2019. Deposition of mullite in peatlands of southern Poland: Implications for recording large-scale industrial processes. Environ. Pollut. 250, 717-727.

Steinnes, E., Sjøbakk, T.E., 2005. Order-of-magnitude increase of Hg in Norwegian peat profiles since the outset of industrial activity in Europe. Environ. Pollut. 137, 365-370.

Syrovetnik, K., Malmstrom, M.E., Neretnieks, I., 2007. Accumulation of heavy metals in the Oostriku peat bog, Estonia: Determination of binding processes by means of sequential leaching. Environ. Pollut. 147, 291-300.

Twardowska, I., Kyziol, J., Goldrath, T., Avnimelech, Y., 1999. Adsorption of zinc onto peat from peatlands of Poland and Izrael. J. Geochem. Explor. 66, 387-405.

Vile, M.A., Kelman Wieder, R., Novak, M., 1999. Mobility of Pb in Sphagnum-derived peat. Biogeochemistry 45, 35-52.

Weiss, D., Shotyk, W., Kramers, J.D., Gloor, M., 1999. Sphagnum mosses as archives of recent and past atmospheric lead deposition in Switzerland. Atmos. Environ. 33, 3751-3763.

Weiss, D., Rausch, N., Mason, T.F.D., Coles, B.J., Wilkinson, J.J., Ukonmaanaho, L., Arnold, T., Nieminen, T., 2007. Atmospheric deposition and isotope biogeochemistry of zinc in ombrotrophic peat. Geochim. Cosmochim. Acta 71, 3498-3517. 